\section{Abstract}

The effects of climate change are escalating and developing and maintaining disaster resilience in communities is a major objective. Yet the active involvement of communities as major stakeholders in building their capacity to prepare, respond to and recover from natural hazards has had less focus in emergency management planning. For communities living in hazard-prone areas, the continuity of risk and disaster awareness and the significance of preparation at the local level can be critical to people's capacity to appropriately respond to disaster events. In 2011, the significant flood event in Brisbane saw community-led response and recovery efforts supported by place-based organisations that traditionally work within communities. However, as communities evolve and change, learnings can dissipate over time. As such, 10 years on from the 2011 floods, how well prepared are communities living in floodprone areas of Brisbane? This paper outlines how community and stakeholder engagement can develop disaster resilience at the local level. The focus is on strong working relationships between participants in emergency management planning and response including communitybased organisations and, by extension, the community.

BASED ON A PAPER PRESENTED AT THE AUSTRALIA \& NEW ZEALAND DISASTER \& EMERGENCY MANAGEMENT CONFERENCE 2020.

\title{
Whose plan is it? The importance of place
}

Peer Reviewed

\section{Laurelle Muir ${ }^{1}$}

1 Resilient Communities Consulting

\section{SUBMITTED \\ 9 November 2020}

\section{ACCEPTED}

1 December 2020

DOI

www.doi.org/10.47389/36.2.54

\section{(c) (1) ()}

(C) 2021 by the authors. License Australian Institute for Disaster Resilience, Melbourne, Australia. This is an open access article distributed under the terms and conditions of the Creative Commons Attribution (CC BY) license (https:// creativecommons.org/ licenses/by/4.0/).

\section{Introduction}

Extreme weather events have caused death and destruction in countries across the globe over the past decades. This highlights the importance of disaster resilience. In Australia, while some communities are still recovering from the most recent fire and flood events, the memory of past events in some communities has declined over time. This raises questions about of how prepared communities are for the next event.

The National Strategy for Disaster Resilience (AttorneyGeneral's Department 2011) outlines an expectation of a level of capacity within communities that anticipates being 'self-reliant and prepared' (p.11). However, there is a lack of any detail about how this capacity is realised in practice at the local level. Such lack of clarity seriously weakens the intent of these aspirations and presents a major challenge to communities to deal with events. This places added burden on the emergency management system and its related agencies.

There is little doubt that resilience is actively being developed in some locations, particularly in rural areas where populations are smaller and the fabric of the community is often strong. However, effectively engaging with urbanised communities to build disaster resilience can be a complex, labour-intensive and ongoing undertaking. For example, it has been 10 years after Brisbane's last major flood event in 2011 and the affected communities and the built environment have changed and evolved since that time. The 'flood memory' is reduced and this is a key factor when designing effective community engagement strategies.

As the flooding inundated communities across Brisbane in 2011, 6 neighbourhood centres provided resources and linked their communities to critical information while also providing outreach services to vulnerable residents (West End Community House 2011). As place-based organisations, these neighbourhood centres have a physical presence in the communities where they deliver services and operate in a localised way to identify, anticipate and respond to local issues and opportunities. They also usually practice from a community-development framework. This research explored how community and stakeholder engagement capitalises on the traditional roles that place-based community organisations play to develop disaster resilience at the local level. 


\section{Methodology}

A case study was used to explore the characteristics of community disaster resilience, community-based disaster management frameworks and cross-sector collaborative approaches. Two place-based community organisations that led community responses to the flood event in Brisbane in 2011 were chosen for this study. In-depth, semi-structured interviews were undertaken with participants from the 2 organisations, as well as with a number of key policy makers and practitioners. Participants contributed their experiences during the flood as they worked in emergency areas of the Queensland Government or Brisbane City Council.

Data analysis leading to the development of a framework to operationalise community disaster resilience at the local level was supported by reflexive thematic analysis. Braun and Clarke (2006, p.591) describe thematic analysis as a qualitative research method, where the researcher plays an active role in the identification of themes from the data. The data were supported by the analysis as well as by insights from the extant literature. Analysis sought to identify the themes that informed the development of frameworks to operationalise community disaster resilience at the local level. National, state, territory and local government disaster management frameworks were also included in this study.

This research was conducted under Queensland University of Technology Ethics Approval Number 1700000122.

\section{Targeting communities in 'place'}

The term 'community engagement' is used frequently by government at all levels to suggest activities that involve varying levels of participation by the public. The United Nations (2005) describes community engagement as:

... a two-way process by which the aspirations, concerns, needs and values of citizens and communities are incorporated at all levels and in all sectors in policy development, planning, decision-making, service delivery and assessment; and by which governments and other business and civil society organisations involve citizens, clients, communities and other stakeholders in these processes.

Purposeful community engagement relies on identifying stakeholders and delivering fit-for-purpose activities tailored to the needs of the target group. Using Brisbane as the case-study area, interviews were held with participants from Brisbane City Council emergency management. The data identified that the size of the city presented challenges to maintaining effective community engagement. In order to address this, the framework proposes directing intensive engagement activities to communities located in hazard-prone areas of the city only. This is an efficient way to direct the resources by focusing on locations of identified need. Community place-based organisations operating in these locations represent critical 'soft entry' point to connect with the community. Their significance relates to local knowledge and the relationships with, and access to, the community (Chen, Liu Y \& Chan 2006; Bach et al. 2010; Thornley et al. 2013).

The major flood event across Brisbane in 2011 provided a meaningful context for this research to understand the significance of community-led efforts. Data from interviews explored the scope of the response, recovery and preparation efforts of the organisations and identified the range of characteristics associated with community resilience that influenced each organisation's ability to deliver. Four themes were synthesised from the data that related to:

- community capacity

- the significance of trust in disaster situations

- the importance of existing relationships and networks

- human connection.

Considering the critical role of place-based organisations, one Queensland Government participant mentioned that the nature of the roles of emergency management agencies can be transient, using terms like 'roll in and out'. However, being part of the community, place-based organisations experience the events with the community. Another participant from a state agency described challenges of working in flood-affected communities where there was an absence of a community centre:

.....we didn't have a community or neighbourhood centre, so we didn't have that coordinator role there... coordinating resources and mobilising people and partnerships is the key one... knowing who to liaise with to bring the right people in for that local response.

Participant response

\section{Developing resilience at the local level}

The expanding body of literature related to resilience adopts the view that the increasing need to respond to disasters cannot be addressed by emergency management agencies acting on their own (Bach et al. 2010, Waugh \& Streib 2006, Simo \& Bies 2007, Kapucu \& Garayev 2012). In recognising the value of, and the necessity for, locally organised efforts, there has been a focus on building the capacity of communities to self-organise (Simo \& Bies 2007, Harris et al. 2018, Bach et al. 2010, Berkes \& Ross 2013, Chen, Liu Y \& Chan 2006). The data from interviews with participants from Brisbane City Council reflected this view and drew out concerns about the effect on council resources if an event with greater consequences than those of 2011 were to occur. One participant commented that 'people are going to have to be more self-sufficient'. The suggestions from state agency participants were that local responses are best led by local governments and that emergency management officers could bring organisations together.

Studies on community-led disaster management models identified that a cross-sectoral approach is critical to building emergency management capability at the local level. Community and stakeholder engagement is a central component of this method (Kapucu \& Garayev 2011, Waugh \& Sylves 2002, Simo 


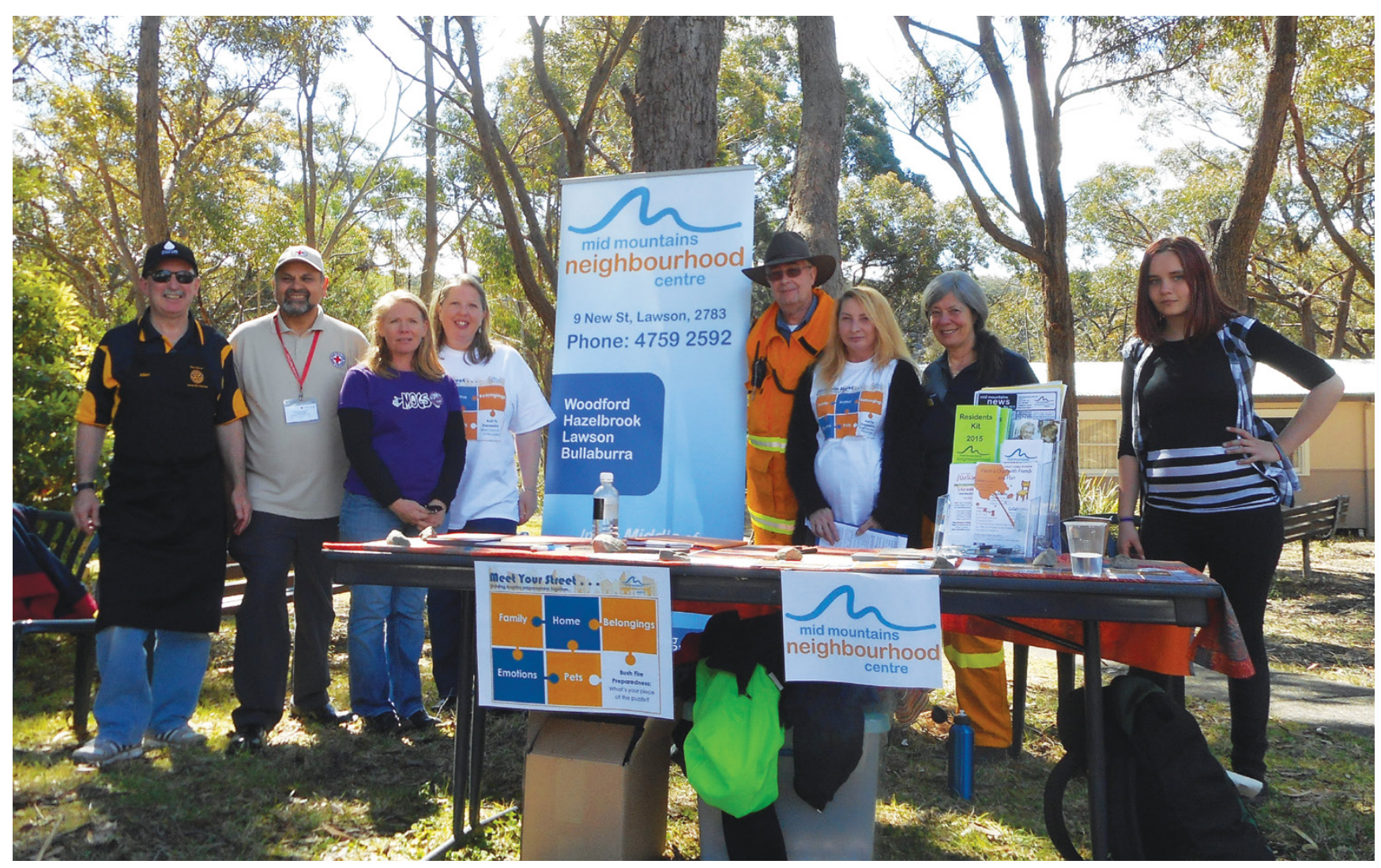

Community organisations delivering their traditional roles within their communities can be effective partners in harnessing community participation in planning activities.

Image: Mountains Outreach Community Services

\& Bies 2007, Bach et al. 2010). From a legislative perspective, Queensland local governments are responsible for engagement with communities (Queensland Government 2018). As part of this facilitation role, local governments are well placed to deliver purposeful stakeholder engagement with state emergency services organisations, volunteer bodies, community organisations and universities to develop working relationships within these sectors.

As key stakeholders in this model, community organisations can be effective partners in harnessing community participation in planning activities. They can also provide significant input into the development of interactive approaches that include people in the community who have experience in disaster events as well as encouraging participation of people from more marginalised or vulnerable parts of the community. Ongoing engagement of local communities in developing pre-disaster planning is important to identify community capacities and tailor the plan to suit community needs (Australian Red Cross 2014, Thornley et al. 2013). Engagement activities that capitalise on existing relationships and networks held by community organisations operating in place can support a whole-of-community approach and encourage participation from local businesses; local institutions such as schools, tertiary institutions and faith-based organisations as well as other place-based community services.

\section{Collaboration and practical support}

An important element of a collaborative approach is the participation of emergency management organisations in engagement activities with the community. Their expertise can build community capacity and can provide those agencies with a level of confidence in their processes and the outcome. Importantly, emergency management agencies that work directly with communities can better understand the diversity, strengths and risks of communities in hazard-prone areas. Collaboration builds relationships and trust (Thornley et al. 2013, Bach et al. 2010, Australian Red Cross 2014). The development of stronger relationships facilitates consistent communication between emergency management agencies and the community. This is a key functional outcome and reduces inefficiency while strengthening community resilience at the local level (Magis 2010; Stys 2011; Kapucu, Yuldashev \& Feldheim 2018).

A significant outcome of this approach is the creation of a culture of awareness that can be developed through planning events and training that include members of the community. Chen, Liu $Y$ and Chan (2006) support public launching of preparation planning to reinforce community awareness and ownership. The staging of scenario exercises involving the community can also sustain a level of awareness by identifying exposure and understanding of the significance of preparation planning. Preparation plans need to be promoted broadly through communication and information 
sharing that is tailored to each community (Paton \& Johnston 2001). A continued presence by collaboration partners at local events also helps to keep plans front of mind for people between disaster events. This also supports awareness by new residents moving to a hazard-prone area.

\section{Building strong working relationships}

International models featuring collaborative approaches to strengthen the capacity of communities have been based on formal training programs that capitalise on the existing capacity and experience of communities. These approaches have incorporated community-based organisations as stakeholders in collaborative initiatives, supported by information and expertise at the community level.

In the Australian context, community organisations are loosely mentioned in the National Strategy for Disaster Resilience (Attorney-General's Department 2011) and in other frameworks. The Australian Council of Social Services (2015) argues that these organisations are rarely included in conversations about what role they could play. As well as a limited role for community organisations in supporting communities, frameworks lack detail on how these organisations can better connect with the emergency management sector.

This study identified an absence of existing relationships between emergency management agencies and communities in hazardprone areas of Brisbane as a challenge to building community resilience. Efforts by 2 organisations to better understand their role and their place in the system, in preparation for the next event led to concerns about a perceived lack of respect for, or confidence in their response and recovery effort. As one interviewee commented:

\section{... it didn't recognise the social capital. It didn't recognise the volunteerism. It didn't recognise the very important social infrastructure that had played out very strongly here and in... other communities obviously. So they really discouraged us from developing anything.}

\section{Participant response}

Recognition by state and local council participants of a role for place-based community organisations in preparation, response and recovery efforts was evident from the interview data. However, engaging community as participants in shared activities, acknowledging local input and supporting community ownership of disaster plans, is contingent on the ability of stakeholders in the system to initiate and develop collaborative relationships and practices. The integration of community organisations operating in place as key stakeholders in the system can have a significant influence on the delivery of this approach.

However, as Bryson, Crosby and Stone (2006, p.44) note, 'collaboration may be necessary and desirable, but the research evidence indicates that it is hardly easy'. Addressing differences between stakeholder groups in terms of how they operate and how they can work together during a disaster are significant elements for consideration in the design of engagement that enables strong working relationships. Stakeholder engagement activities that focus on a shared understanding of roles and responsibilities, respect for local knowledge and experience and a recognition of community flexibility can assist in building trust and cooperation.

Studies on major disasters have identified the importance of providing adequate financial resourcing to community organisations to enable their participation in disaster resilience in communities (Cretney 2016; Kapucu, Yuldashev \& Feldheim 2018; Goode et al. 2015). Community organisations receive a major portion of their funding through government programs and are therefore practised in reporting and delivering outputs and acquittals. In terms of accountability, resourcing for their role could be tied to the successful development of a preparation plan, staff attendance at training and collaboration events. This approach considers the return on investment that governments can achieve as communities build a capacity to respond to disasters and create an effective disaster response system (Goode et al. 2015, Cretney 2016).

\section{Conclusion}

The loss over time of community disaster capacity developed through previous local responses is a critical issue. The sustainability of social capital and community capacity that can support the replication of a community's ability to self-organise in any future event is not guaranteed. Additionally, international trends towards a recognition of the limitations of emergency management systems highlight the necessity to provide support to locally organised efforts, through building the capacity of communities to self-organise. A significant aspect of the approach outlined in this paper is the ability to develop a sustainable culture of awareness of disaster risk and preparation arrangements among communities through ongoing community and stakeholder engagement.

This paper has drawn on existing studies to suggest a strategy that departs from a traditional 'top down' approach to disaster resilience, advocating a collaborative cross-sector approach that would see the integration of community organisations operating in place as stakeholders in the emergency management system. Data from participant interviews showed how relationships held by place-based community organisations with their communities can present a crucial entry point for engagement activities that assist emergency management agencies working with communities to develop and promote ownership of local preparation plans.

Operationalising community disaster resilience at the local level can be improved through providing communities with opportunities be active participants in the system. The willingness of emergency management agencies to formalise roles for the community sector, and by extension, the community, could create pathways to prepared and resilient communities.

\section{References}

Attorney-General's Department 2011, National Strategy for Disaster Resilience - Building the Resilience of our Nation to Disasters. At: https://knowledge.aidr.org.au/media/2153/ nationalstrategyfordisasterresilience.pdf. 
Australian Red Cross 2014, National Disaster Resilience Roundtable Report, Beyond the Blanket: The role of not-for-profits and nontraditional stakeholders in emergency management, 2nd National Disaster Resilience Roundtable Report. At: www.redcross.org. au/getmedia/e93ca7b3-efa5-4874-b75d-8b62a7fa908e/2014Disaster-Resilience-Roundtable-report_1.pdf.aspx.

Bach R, Doran R, Gibb L, Kaufman D \& Settle K 2010, Policy Changes in Supporting Community Resilience, presented at the London Workshop of the Multinational Community Resilience Working Group, November 4-5, 2010. At: www.fema.gov/medialibrary-data/20130726-1752-25045-947/policy_challenges_ in_supporting_community_resilience_london_2010for_ release122210.pdf.

Berkes F \& Ross H 2013, Community Resilience: Toward an Integrated Approach. Society \& Natural Resources, vol. 26, no. 1, pp.5-20. doi: 10.1080/08941920.2012.736605

Braun V \& Clarke V 2006, Using Thematic Analysis in Psychology. Qualitative Research in Psychology, vol. 3, no. 2.

Bryson JM, Crosby BC \& Stone MM 2006, The Design and Implementation of Cross-Sector Collaborations: Propositions from the Literature. Public Administration Review, vol. 66, no. 1, pp.44-55. doi.org/10.1111/j.1540-6210.2006.00665.x

Chen L, Liu Y \& Chan K 2006, Integrated Community-Based Disaster Management Program in Taiwan: A Case Study of ShangAn Village. Natural Hazards, vol. 37, pp.209-223. doi 10.1007/ s11069-005-4669-5

Cretney RM 2016, Local responses to disaster: The value of community led post disaster response action in a resilience framework, Disaster Prevention and Management, vol. 25, no. 1, pp.27-40.

Harris C, McCarthy K, Liang Liu E, Klein K, Swienton R, Prins P \& Waltz T 2018, Expanding Understanding of Response Roles: An Examination of Immediate and First Responders in the United States. International Journal of Environmental Research and Public Health, vol. 15, no. 3. doi:10.3390/ijerph15030534

Goode N, Spencer C, McArdle D, Salmon P \& Archer F 2015, Characteristics of a disaster resilient Victoria: Consensus from those involved in emergency management activities. Australian Journal of Emergency Management, vol. 30, no. 3, pp.42-47. At: https://knowledge.aidr.org.au/resources/ajem-jul-2015characteristics-of-a-disaster-resilient-victoria-consensus-fromthose-involved-in-emergency-management-activities/.

Magis K 2010, Community Resilience: An Indicator of Social Sustainability. Society and Natural Resources, vol. 23, no. 5, pp.401-416. doi:10.1080/08941920903305674

Kapucu N \& Garayev V 2011, Collaborative Decision-Making in Emergency and Disaster Management. International Journal of Public Administration, vol. 34, no. 6, pp.366-375. doi:10.1080/019 00692.2011.561477

Kapucu N \& Garayev V 2012, Designing, Managing, and Sustaining Functionally Collaborative Emergency Management Networks. The American Review of Public Administration, vol. 43, no. 3, pp.312-330. doi:10.1177/0275074012444719
Kapucu N, Yuldashev F \& Feldheim MA 2018, Nonprofit Organizations in Disaster Response and Management: A Network Analysis. Journal of Economics and Financial Analysis, Tripal Publishing House, vol. 2, no. 1, pp.69-98.

Paton D \& Johnston D 2001, Disasters and communities: vulnerability, resilience and preparedness. Disaster Prevention and Management: An International Journal, vol. 10, no. 4, pp.270-277. doi:10.1108/EUM0000000005930

Queensland Government 2018, Queensland State Disaster Management Plan. At: www.disaster.qld.gov.au/cdmp/ Documents/Queensland-State-Disaster-Management-Plan.pdf.

Simo G \& Bies AL 2007, The Role of Nonprofits in Disaster Response: An Expanded Model of Cross-Sector Collaboration. Public Administration Review, vol. 67, pp.125-142.

Stys JJ 2011, Non-Profit Involvement in Disaster Response and Recovery. Prepared by Strategic Decision Associates for the Center for Law, Environment, Adaptation and Resources at the University of North Carolina School of Law.

Thornley L, Ball J, Signal L, Lawson-Te Aho K \& Rawson E 2013, Building Community Resilience: Learning from the Canterbury Earthquakes. Research Report. At: www.communityresearch.org. $\mathrm{nz} /$ research/building-community-resilience-learning-from-thecanterbury-earthquakes/.

United Nations 2005, Brisbane Declaration on Community Engagement. First International Conference on Engaging Communities, Brisbane, Australia. At: www.ncdd.org/exchange/ files/docs/brisbane_declaration.pdf.

Waugh Jr. WL \& Streib G 2006, Collaboration and Leadership for Effective Emergency Management. Public Administration Review, vol. 66, no. s1, pp.131-140. doi.org/10.1111/j.15406210.2006.00673.x

Waugh Jr. WL \& Sylves RT 2002, Organising the War on Terrorism. Public Administration Review, vol. 62, Special Issue, pp.145-153.

West End Community House 2011, Strengthening people and places: the role and value of community and neighbourhood centres. At: http://communityplus.org.au/wp-content/ uploads/2015/03/Strengthening-people-place-the-role-andvalue-of-community-neighbourhood-centres.pdf.

\section{About the author}

Laurelle Muir is the Director of Resilient Communities Consulting and has 20 years' experience in community engagement, social planning and community development. Her experiences in coordinating a major evacuation centre during the 2011 floods and the management of community-development recovery projects inspired a strong interest in the development of community disaster resilience. 